\title{
APLICAÇÃO DE RADIAÇÃO UV ARTIFICIAL E SOLAR NO TRATAMENTO FOTOCATALÍTICO DE EFLUENTES DE CURTUME
}

\author{
Salomão de Andrade Pascoal* \\ Universidade Federal da Paraíba/Universidade Estadual da Paraíba, Av. das Baraúnas, s/n, \\ 58109-790 Campina Grande - PB, Brasil \\ Carlos Antônio Pereira de Lima, José Tavares de Sousa, Geralda Gilvania Cavalcante de Lima e \\ Fernando Fernandes Vieira \\ Departamento de Química, Centro de Ciências e Tecnologia, Universidade Estadual da Paraíba, Av. das Baraúnas, s/n, \\ 58109-790 Campina Grande - PB, Brasil
}

Recebido em 18/1/06; aceito em 15/1/07; publicado na web em 17/7/07

\begin{abstract}
APPLICATION OF ARTIFICIAL AND SOLAR UV RADIATION IN THE PHOTOCATALYTIC TREATMENT OF A TANNERY EFFLUENT. Tannery effluents are very dangerous for the environment since they contain large amounts of dangerous and biorecalcitrant contaminants (organic matter and $\mathrm{Cr}(\mathrm{VI})$ ). This paper reports the efficiency of heterogeneous photocatalysis, based on the application of solar and artificial radiation, furnished by UV lamps, using $\mathrm{TiO}_{2}$ fixed on a flat plate, in the treatment of synthetic effluents. The results of $\mathrm{COD}$ and $\mathrm{Cr}(\mathrm{VI})$ demonstrate that the use of solar radiation is the most efficient way to perform the photocatalytic treatment of these effluents since a minimum removal of 62 and $61 \%$ was observed for $\mathrm{Cr}(\mathrm{VI})$ and organic matter, respectively.
\end{abstract}

Keywords: heterogeneous photocatalysis; artificial radiation; solar radiation.

\section{INTRODUÇÃO}

A maior parte dos impactos ambientais gerados pela sociedade contemporânea de países desenvolvidos ou em desenvolvimento tem sua gênese no setor industrial. Este setor é um grande consumidor de recursos naturais e um grande produtor de dejetos que, geralmente, são descartados no meio ambiente - no estado in natura ou ineficientemente tratados - em especial, nos ecossistemas aquáti$\cos ^{1}$. As indústrias de curtimento de couro são valorosas representantes do extraordinário potencial poluidor do segmento industrial. Todo o processo produtivo do couro curtido consome grande quantidade de água e, por conseguinte, gera também expressiva quantidade de efluentes líquidos e resíduos sólidos. Em média, a produção de $250 \mathrm{~kg}$ de couro curtido é feita a partir de $1 \mathrm{t}$ de pele salgada, sendo necessária a aplicação de $30.000 \mathrm{~L}$ de água para todo o processo de curtimento $^{2}$. Assim, em média, as indústrias de curtume finalizam cerca de 20 a $30 \%$ de sua matéria-prima, resultando na produção média de $600 \mathrm{~kg}$ de resíduos sólidos e $50 \mathrm{~m}^{3}$ de efluentes líquidos (com $250 \mathrm{~kg}$ de DQO e $100 \mathrm{~kg}$ de DBO) ${ }^{3}$.

As águas residuárias de curtumes já são submetidas a processos de tratamento preliminar (gradeamento, mistura e homogeneização, retenção de gordura e lançamento em vazão regularizada), primário (coagulação, floculação e decantação) e secundário (aplicação de lodos ativados, valos de oxidação, lagoas aeradas, facultativas etc) ${ }^{4}$. No entanto, em indústrias de grande porte essas etapas de tratamento não se mostram eficazes para que os efluentes tratados tenham as características desejáveis para serem descartados no meio ambiente, especialmente em relação aos teores de material orgânico e cromo. As afirmações anteriores podem ser contextualizadas com dois exemplos reais de produção de efluentes de curtume perigosos para o meio ambiente. Segundo Gomes et al. ${ }^{5}$, o curtume Santo Agostinho, localizado no município de Juazeiro do Norte (CE), lança para a

*e-mail: salomaopascoal@hotmail.com rede coletora da Companhia de Água e Gerenciamento de Esgotos do Estado do Ceará (CAGECE) efluentes tratados com $1.866 \mathrm{mg}$ de $\mathrm{O}_{2} \mathrm{~L}^{-1}$ de DQO, $17.254 \mathrm{mg} \mathrm{L}^{-1}$ de sólidos totais e 27,8 $\mathrm{mg} \mathrm{L}^{-1}$ de óleos e graxas. A produção de efluentes com grande quantidade de cromo pode ser contextualizada a partir dos trabalhos de Verma et al. ${ }^{6} \mathrm{e}$ Srinath et al. ${ }^{7}$. Segundo esses autores, na Índia a produção de couro concentra-se nos estados de Unnao, Kanpur e Uttar Pradesh, havendo em Unnao uma central de tratamento dos efluentes dos curtumes (CETP) pertencentes aos estados de Unnao e Uttar Pradesh. Os curtumes desses estados produzem efluentes com $62 \pm 34 \mathrm{mg} \mathrm{L}^{-1} \mathrm{de}$ cromo total e com 3,0 $\pm 1,5 \mathrm{mg} \mathrm{L}^{-1}$ de $\mathrm{Cr}(\mathrm{VI})$. Mesmo com o tratamento dos efluentes na CETP a quantidade de cromo continua elevada, permanecendo nos efluentes $5,48 \pm 2,42 \mathrm{mg} \mathrm{L}^{-1}$ de cromo total e $0,96 \pm 0,22 \mathrm{mg} \mathrm{L}^{-1}$ de $\mathrm{Cr}(\mathrm{VI})$.

Nas situações em que os processos clássicos de tratamento de efluentes já alcançaram seus limites de eficácia, sendo esta reduzida, torna-se necessária a aplicação de tratamentos terciários ou polimentos finais. Atualmente, o avanço científico permitiu o aperfeiçoamento e a aplicação dos Processos Oxidativos Avançados (POA), que são técnicas que se aplicam eficazmente no tratamento de compostos recalcitrantes, ou seja, são capazes de eliminar compostos resistentes aos tratamentos primário (físico e químico) e secundário (biológico), podendo ser aplicadas a compostos inorgânicos ou orgânicos (biodegradáveis e não biodegradáveis) ${ }^{8}$. Com relação aos compostos orgânicos, a maior vantagem desses processos é a real destruição do poluente tratado, transformando-os em produtos inertes $\left(\mathrm{CO}_{2}, \mathrm{H}_{2} \mathrm{O}\right.$ e ácidos minerais), fato que não ocorre com os processos convencionais de tratamento que promovem apenas transferência de fase do poluente ${ }^{9,10}$.

Dentre os POAs, destaca-se a fotocatálise heterogênea. Este é um processo que alia reações de oxi-redução induzidas pela radiação ultravioleta e que ocorre em meio aquoso, fazendo uso de um fotocatalisador, aliando a fotoquímica com a catálise. Na fotocatálise, o fotocatalisador absorve energia dos fótons da radiação 
ultravioleta, gerando radicais hidroxila $(\cdot \mathrm{OH})$ altamente reativos e capazes de mineralizar a matéria orgânica ${ }^{11-13}$.

Os processos fotocatalíticos usam diversos fotocatalisadores (chamados de semicondutores) como por exemplo, $\mathrm{TiO}_{2}, \mathrm{CdS}, \mathrm{ZnO}$, $\mathrm{ZnS}, \mathrm{WO}_{3}, \mathrm{BiO}_{3}$ e $\mathrm{Fe}_{2} \mathrm{O}_{3}$. Destes, o dióxido de titânio é o mais utilizado, devido às seguintes características: não tem toxicidade, é resistente à corrosão, tem preço acessível, é abundante, é insolúvel em água, tem fotoestabilidade, possui estabilidade química em ampla faixa de $\mathrm{pH}$, tem banda de passagem ("band gap") na região do UV e pode ser usado à temperatura ambiente ${ }^{11,14}$. $\mathrm{O} \mathrm{TiO}_{2}$ pode existir nas formas alotrópicas anatase, rutilo e brookite, sendo a mistura das formas anatase e rutilo, na proporção de 70:30, a mais utilizada $^{12,15}$. Na fotocatálise o $\mathrm{TiO}_{2}$ pode ser utilizado em suspensão ou imobilizado. Em suspensão, a principal vantagem é a inexistência de resistência à transferência de massa entre o substrato e o fotocatalisador. Esta forma de uso apresenta algumas desvantagens: necessidade de separação do fotocatalisador do substrato, após o tratamento e o $\mathrm{TiO}_{2}$ em altas concentrações pode conferir alta turbidez, podendo impedir a passagem de luz por toda a mistura aquosa. $\mathrm{O} \mathrm{TiO}_{2}$ pode ser imobilizado em várias matrizes, podendo-se utilizar pérolas de sílica ou grandes superfícies planas, a exemplo de placas de vidro jateado ${ }^{15}$.

$\mathrm{O}$ fotocatalisador é formado por bandas de valência (BV) e por bandas de condução (BC), havendo entre ambas uma região energética denominada de "band gap", que possui valor inicial de 3,2 eV. Este valor representa a quantidade mínima de energia necessária para que ocorra migração de um elétron da banda de valência para a banda de condução ${ }^{11,16}$. Com a absorção de energia na forma de fótons, o $\mathrm{TiO}_{2}$ terá elétrons da $\mathrm{BV}$ migrando para a BC. Na BV haverá formação de lacunas chamadas de "positive hole $\left(\mathrm{h}^{+}\right)$" capazes de gerar radicais hidroxila; estas lacunas possuem potenciais bastante positivos $(+2 \mathrm{a}+3,5 \mathrm{~V})$ que permitem a oxidação de qualquer composto orgânico exposto a esse potencial. Os radicais hidroxila advêm de íons hidroxila ou de moléculas de água adsorvidas à superfície da molécula do $\mathrm{TiO}_{2}$ que cedem elétrons para a BV. Assim, é o elétron fornecido pela $\mathrm{OH}^{-}$e/ou $\mathrm{H}_{2} \mathrm{O}$, ambos adsorvidos na superfície do fotocatalisador, que permitem que o $\mathrm{TiO}_{2}$ volte ao seu estado de equilíbrio anterior à absorção da energia fotônica, garantindo a eletro-neutralidade do fotocatalisador. Os elétrons que migram para a banda de condução são os responsáveis pelas reações de redução, devido aos potenciais de $0 \mathrm{a}-1 \mathrm{~V}$. Esta é a banda responsável pela redução de elementos inorgânicos, a exemplo do cromo que terá a sua espécie hexavalente convertida para trivalente; este fenômeno só ocorre quando se utilizam fontes luminosas com comprimento de onda menor que $387 \mathrm{~nm}$. Essa faixa de comprimento de onda permite a utilização da radiação UV proveniente do sol, visto que os comprimentos de onda nesta faixa representam 4 a $6 \%$ de toda a radiação solar que atinge a superfície terrestre ${ }^{11,15-17}$.

A etapa de adsorção, entre o $\mathrm{TiO}_{2}$ e as substâncias a serem reduzidas e oxidadas, é de grande importância para a fotocatálise, especialmente dos aceptores de elétrons, pois são eles que impedem o retorno do elétron da $\mathrm{BC}$ para a $\mathrm{BV}$; quando ocorre este retorno há emissão de calor pelo fotocatalisador. A adsorção é regida por forças eletrostáticas de atração e repulsão estabelecidas pelas cargas superficiais do fotocatalisador e do substrato, sendo o $\mathrm{pH}$ do meio o fator determinante da carga superficial do $\mathrm{TiO}_{2}$ : em $\mathrm{pH}$ menor que 6 , a superfície do fotocatalisador terá carga positiva e em $\mathrm{pH}$ maior que 6 terá carga negativa. Portanto, faz-se necessário que as substâncias a serem tratadas (em especial os aceptores de elétrons) tenham cargas superficiais opostas ao $\mathrm{TiO}_{2}{ }^{16,18}$. A Figura 1 mostra um esquema geral do processo fotocatalítico heterogêneo citado.

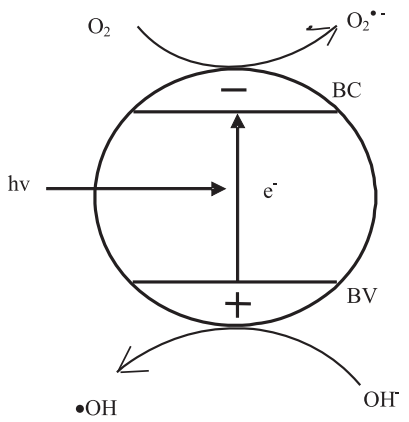

Figura 1. Esquema representativo da partícula de um semicondutor e geração

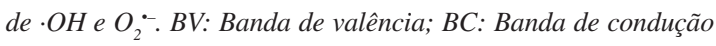

Segundo Daniel ${ }^{15}$, os processos fotocatalíticos possuem várias vantagens, tais como amplo espectro de mineralização de compostos orgânicos; eliminação da necessidade de adição de oxidantes químicos; não necessitam de adição de receptores de elétrons; o fotocatalisador pode ser reaproveitado e, o fotocatalisador pode ser excitado com radiação solar. Estas vantagens justificam a prática da fotocatálise heterogênea em países tropicais, pois segundo Luiz apud Ferreira e Daniel ${ }^{14}$, nações como o Brasil possuem em média $4 \times 10^{22} \mathrm{~J} /$ ano de energia solar disponível, ou seja, aproximadamente $1,2 \times 10^{21} \mathrm{~J} /$ ano de energia ultravioleta atinge a superfície territorial brasileira.

Nos efluentes de indústrias de curtume, o $\mathrm{Cr}(\mathrm{III})$ e o $\mathrm{Cr}(\mathrm{VI})$ são mais resistentes aos processos convencionais de tratamento que a matéria orgânica. Assim, o objetivo deste trabalho foi investigar a remoção quantitativa de $\mathrm{Cr}(\mathrm{VI})$ (em quantidade elevada) e de matéria orgânica em amostras sintéticas representativas de efluentes de curtume, fazendo uso da fotocatálise heterogênea. O presente trabalho propõe uma alternativa de polimento final para efluentes líquidos provenientes de curtumes. Utilizaram-se como fontes de radiação ultravioleta o sol e lâmpadas germicidas $(\lambda=250 \mathrm{~nm})$. O reator utilizado foi de placa plana, do tipo leito fixo de filme fino, com $\mathrm{TiO}_{2}$ imobilizado.

\section{PARTE EXPERIMENTAL}

\section{Descrição da montagem experimental}

Os experimentos foram instalados e conduzidos no Laboratório de Saneamento Ambiental da Universidade Estadual da Paraíba, com coordenadas geográficas de $07^{\circ} 13^{\prime} \mathrm{S}$ e $35^{\circ} 52^{\prime} \mathrm{W}$ e altitude de $560 \mathrm{~m}$. Os ensaios foram realizados em reator de placa de vidro jateado de $6 \mathrm{~mm}$ de espessura e dimensões de $0,70 \mathrm{~m}$ de comprimento por $0,50 \mathrm{~m}$ de largura. Nesta placa, imobilizou-se o fotocatalisador dióxido de titânio em área de $0,35 \mathrm{~m}^{2}$, obtendo-se uma concentração de $10 \mathrm{~g}$ de $\mathrm{TiO}_{2} \mathrm{~m}^{-2}$, seguindo-se a metodologia proposta por Nogueira ${ }^{17}$. O $\mathrm{TiO}_{2}$ empregado foi o P-25 DegussaHülls (80\% anatase e $20 \%$ rutilo, com área superficial de $50 \mathrm{~m}^{2} \mathrm{~g}$ ${ }^{1}$ e tamanho médio das partículas de $21 \mathrm{~nm}$ ). A Figura 2 mostra o reator fotocatalítico utilizado.

\section{Descrição dos experimentos}

Os experimentos foram realizados com vazão de $26,36 \mathrm{~L} \mathrm{~h}^{-1}$. O ângulo de inclinação da placa com a horizontal foi de $7^{\circ}$, tendo em vista a latitude da cidade de Campina Grande. Essa inclinação foi necessária para que a radiação solar pudesse incidir perpendicularmente na placa de vidro ${ }^{14}$. $\mathrm{O}$ ângulo de inclinação adotado e a vazão empregada permitiram a obtenção de um tempo de retenção hidráulica de $8,13 \mathrm{~s}$, um volume de reator de 0,06 L e uma lâmina 


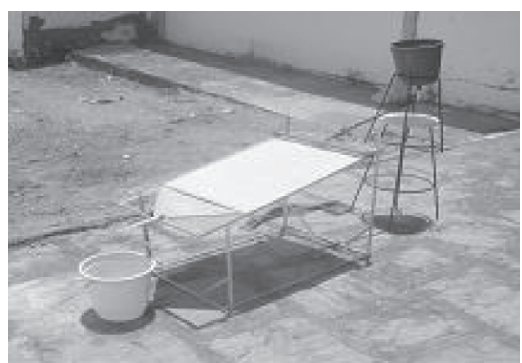

Figura 2. Reator fotocatalítico de placa plana

d'água uniforme e delgada de $170,30 \mu \mathrm{m}$. O fotorreator foi instalado de modo que a placa de vidro com o fotocatalisador ficasse voltada para o Norte e protegida de sombreamentos oriundos de edificações ou de vegetações circunvizinhas.

As amostras analisadas foram preparadas a partir de soluções estoque de $\mathrm{Cr}(\mathrm{VI})$ (500 $\mathrm{mg} \mathrm{L}^{-1}$ ) diluídas em água de abastecimento público local. As amostras tiveram concentrações iniciais de $15 \mathrm{mg}$ de $\mathrm{Cr}(\mathrm{VI}) \mathrm{L}^{-1}$ e volume final de $5 \mathrm{~L}$. A água do sistema de abastecimento foi escolhida por ser a fonte hídrica para uma produção em escala real. A matéria orgânica utilizada, para ser adicionada na amostra, foi massa de patê de carne industrializado (Öderich) vendido no comércio local, sendo sempre adicionada a mesma quantidade de massa $(5,7 \mathrm{~g}$ para o volume total de $5 \mathrm{~L}$ ). Essa massa foi adotada por fornecer uma DQO próxima de 700 $\mathrm{mg}$ de $\mathrm{O}_{2} \mathrm{~L}^{-1}$. Em ensaios preliminares estabeleceu-se a relação entre a massa de patê e a DQO. Segundo o fabricante, o patê é constituído por carnes suína e bovina, fígado suíno, toucinho, miúdos de bovino, caldo de carne, amido, proteína vegetal, sal e especiarias, polifosfatos alimentícios e nitrito de sódio. A adoção de uma DQO de concentração próxima de $700 \mathrm{mg}$ de $\mathrm{O}_{2} \mathrm{~L}^{-1}$ teve como referência o trabalho de Vieira et al. ${ }^{19}$. Segundo esses autores, o curtume-escola do Centro de Tecnologia do Couro e do Calçado Albano Franco (CTCC/SENAI-PB) produz efluente tratado (submetido a tratamentos físico-químico e biológico por lodo ativado) com DQO de concentração de $626 \mathrm{mg} \mathrm{O}_{2} \mathrm{~L}^{-1}$. As amostras tiveram pH ajustado para ácido (3), com adição de ácido sulfúrico diluído e hidróxido de potássio em solução, usando-se um pHmetro para aferição.

Os experimentos foram do tipo batelada, com recirculação manual, consistindo no enchimento de um recipiente colocado a montante do reator que conduzia a amostra para o topo da placa. Essa última condição permitiu que a amostra escoasse pela placa (fazendo uso da força peso do líquido), formando uma lâmina delgada e uniforme, sendo captada por outro recipiente colocado a jusante do reator. O tempo de duração da recirculação foi de $4 \mathrm{~h}$. Para os experimentos expostos à radiação solar, os trabalhos sempre se iniciaram às 10:00 e terminaram às 14:00 h. A cada $30 \mathrm{~min}$, alíquotas foram coletadas para as determinações físicas e químicas. Devido às altas taxas de evaporação, foi necessário realizar a reposição de volume durante a execução dos experimentos, a fim de evitar aumento de concentração da amostra. Para tal, utilizou-se a água de abastecimento público sem nenhum ajuste de $\mathrm{pH}$.

Como fontes artificiais de radiação UV, foram utilizadas três lâmpadas germicidas (15W) com $\lambda=250 \mathrm{~nm}$, dispostas em três refletores semi-circulares, posicionados logo acima da placa de vidro com o $\mathrm{TiO}_{2}$, sempre na mesma posição e com as mesmas lâmpadas em cada refletor, havendo uma distância de $12 \mathrm{~cm}$ entre as lâmpadas e a superfície do fotorreator. A Figura 3 mostra uma representação esquemática dos refletores semi-circulares com as lâmpadas. A Figura 4 mostra os refletores posicionados no reator.

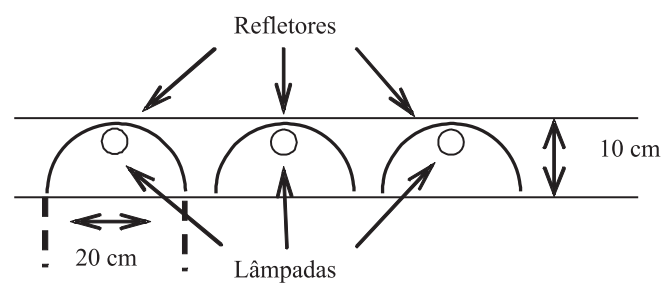

Figura 3. Representação esquemática dos refletores semi-circulares

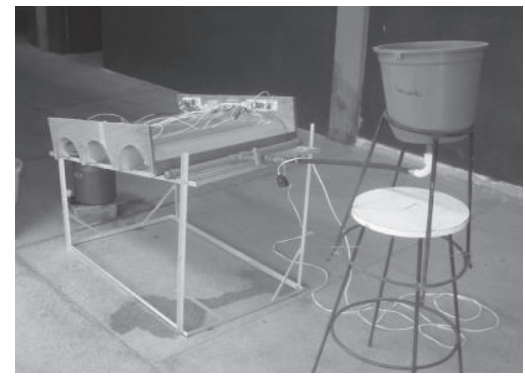

Figura 4. Refletores semi-circulares montados acima do fotorreator

\section{Caracterização física e química das amostras}

As amostras foram submetidas às seguintes análises físicas e químicas: temperatura, oxigênio dissolvido (OD), alcalinidade, turbidez, sólidos suspensos totais (SST), sólidos suspensos voláteis (SSV), demanda química de oxigênio (DQO) e cromo hexavalente $(\mathrm{Cr}(\mathrm{VI}))$. Para as medidas de temperatura, utilizou-se um termômetro de mercúrio. Para OD e turbidez utilizaram-se medidores eletrônicos específicos das marcas Clandom (modelo YSI Moder 54A) e M. Brilhante LTDA (modelo TB 1000), respectivamente. Para as determinações dos SST e das suas frações, da concentração do Cr(VI) e de DQO utilizaram-se metodologias presentes em APHA $^{20}$. Todas as análises foram realizadas no Laboratório de Saneamento Ambiental da Universidade Estadual da Paraíba - Campus I (Campina Grande$\mathrm{PB})$.

A radiação UV foi medida com dois radiômetros portáteis (sendo um específico para $254 \mathrm{~nm}$ e o outro para $365 \mathrm{~nm}$ ) da Cole-Parmer Instrument, Co., modelo VLX Radiometer, série 9811.

\section{RESULTADOS E DISCUSSÃO}

Foram realizados 12 experimentos, sendo 6 com exposição à radiação solar (ordenados de 1 a 6) e os demais com exposição a lâmpadas germicidas (ordenados de A até F). Nas Tabela 1 estão os resultados da caracterização física e química das amostras, mostrando valores antes (afluente) e depois das $4 \mathrm{~h}$ de tratamento (efluente).

Os valores de temperatura mostram que apenas nos experimentos com exposição solar houve absorção de radiação IV, seguramente a principal causa da alta taxa de evaporação das amostras. Com as lâmpadas não se observou aquecimento do fotolisado. No entanto, observou-se significativa evaporação das amostras, muito provavelmente em virtude do fluxo de ar. Segundo Srithar e Mani ${ }^{21}$, nos reatores de placa plana os fatores que promovem a evaporação das amostras aquosas são o aumento da incidência de insolação, aumento da ação da velocidade do vento (que atinge o reator) e aumento do fluxo de massa sobre o reator.

Os resultados de OD referentes a todos os experimentos com lâmpadas são os que melhor representam o aumento de concentração de oxigênio dissolvido ao longo das $4 \mathrm{~h}$ de trabalho. Esse aumento de OD não é desejável para o processo como um todo, já que 
Tabela 1. Caracterização física e química dos afluentes e efluentes das amostras expostas à radiação solar e de lâmpadas germicidas.

\begin{tabular}{|c|c|c|c|c|c|c|c|c|c|c|}
\hline UV & Exp & Var. & $\begin{array}{l}\text { Temp } \\
\left({ }^{\circ} \mathrm{C}\right)\end{array}$ & $\begin{array}{c}\mathrm{OD} \\
\left(\mathrm{mg} \mathrm{L}^{-1}\right)\end{array}$ & $\begin{array}{c}\text { Alcalinidade } \\
\left(\mathrm{mg} \mathrm{CaCO}_{3} \mathrm{~L}^{-1}\right)\end{array}$ & $\begin{array}{c}\mathrm{Cr}(\mathrm{VI}) \\
\left(\mathrm{mg} \mathrm{L}^{-1}\right)\end{array}$ & $\begin{array}{c}\text { DQO } \\
\left(\mathrm{mg} \mathrm{L}^{-1}\right)\end{array}$ & $\begin{array}{c}\text { Turbidez } \\
\text { (NTU) }\end{array}$ & $\begin{array}{c}\mathrm{SST} \\
\left(\mathrm{mg} \mathrm{L}^{-1}\right)\end{array}$ & $\begin{array}{c}\text { SSV } \\
\left(\mathrm{mg} \mathrm{L}^{-1}\right)\end{array}$ \\
\hline \multirow[t]{12}{*}{ Solar } & \multirow[t]{2}{*}{1} & Aflu. & 25 & - & 0,00 & 13,91 & 560 & 347 & 342 & 338 \\
\hline & & Eflu. & 27 & - & 50,41 & $0,92(93 \%)$ & $39(93 \%)$ & $149(57 \%)$ & $98(71 \%)$ & $98(71 \%)$ \\
\hline & \multirow[t]{2}{*}{2} & Aflu. & - & 7,30 & 0,00 & 15,18 & 738 & 207 & 114 & 114 \\
\hline & & Eflu. & - & 7,40 & 24,19 & $0,00(100 \%)$ & $269(64 \%)$ & $74,4(64 \%)$ & $84(26 \%)$ & $84(26 \%)$ \\
\hline & \multirow[t]{2}{*}{3} & Aflu. & 25 & - & 0,00 & 14,23 & 717 & 197 & 297 & 282 \\
\hline & & Eflu. & 28 & - & 24,19 & $0,56(96 \%)$ & $283(61 \%)$ & $58,7(70 \%)$ & $70(76 \%)$ & $61(78 \%)$ \\
\hline & \multirow[t]{2}{*}{4} & Aflu. & 25 & - & 0,00 & 15,20 & 595 & 152 & 286 & 286 \\
\hline & & Eflu. & 26 & - & 24,19 & $1,07(93 \%)$ & $165(72 \%)$ & $52,5(65 \%)$ & $64(78 \%)$ & $64(78 \%)$ \\
\hline & \multirow[t]{2}{*}{5} & Aflu. & 25 & - & 0,00 & 15,01 & 728 & 200 & 298 & 298 \\
\hline & & Eflu. & 28 & - & 10,08 & $2,54(83 \%)$ & $240(67 \%)$ & $50,9(75 \%)$ & $78(74 \%)$ & $78(74 \%)$ \\
\hline & \multirow[t]{2}{*}{6} & Aflu. & 25 & 7,29 & 0,00 & 14,38 & 730 & 125 & 288 & 288 \\
\hline & & Eflu. & 27 & 7,35 & 16,13 & $5,47(62 \%)$ & $230(68 \%)$ & $42,9(66 \%)$ & $62(78 \%)$ & $62(78 \%)$ \\
\hline \multirow[t]{12}{*}{ Lâmpadas } & \multirow[t]{2}{*}{ A } & Aflu. & 25 & 7,30 & 0,00 & 15,51 & 585 & 243 & 223 & 223 \\
\hline & & Eflu. & 25 & 7,62 & 30,24 & $7,43(52 \%)$ & $200(66 \%)$ & $59,4(76 \%)$ & $52(77 \%)$ & $52(77 \%)$ \\
\hline & \multirow[t]{2}{*}{ B } & Aflu. & 25 & 7,09 & 0,00 & 14,10 & 680 & 150 & 307 & 295 \\
\hline & & Eflu. & 25 & 7,68 & 30,24 & $3,71(74 \%)$ & $248(64 \%)$ & $50,7(66 \%)$ & $107(65 \%)$ & $87(71 \%)$ \\
\hline & \multirow[t]{2}{*}{$\mathrm{C}$} & Aflu. & 25 & 7,00 & 0,00 & 15,59 & 630 & 140 & 241 & 228 \\
\hline & & Eflu. & 25 & 7,62 & 16,13 & $6,34(59 \%)$ & $185(71 \%)$ & $45,5(68 \%)$ & $72(70 \%)$ & $72(68 \%)$ \\
\hline & \multirow[t]{2}{*}{$\mathrm{D}$} & Aflu. & 25 & 6,51 & 0,00 & 14,62 & 653 & 155 & 301 & 293 \\
\hline & & Eflu. & 25 & 7,15 & 16,13 & $5,88(60 \%)$ & $223(66 \%)$ & $55,2(64 \%)$ & $95(68 \%)$ & $94(68 \%)$ \\
\hline & \multirow[t]{2}{*}{ E } & Aflu. & 25 & 6,43 & 0,00 & 15,16 & 648 & 152 & 129 & 129 \\
\hline & & Eflu. & 25 & 7,19 & 0,00 & $6,90(54 \%)$ & $304(53 \%)$ & $101(34 \%)$ & $101(22 \%)$ & $101(22 \%)$ \\
\hline & \multirow[t]{2}{*}{ F } & Aflu. & 25 & 6,49 & 0,00 & 15,33 & 808 & 205 & 111 & 111 \\
\hline & & Eflu. & 25 & 7,32 & 8,06 & $7,18(53 \%)$ & $292(64 \%)$ & $71,6(65 \%)$ & $96(14 \%)$ & $96(14 \%)$ \\
\hline
\end{tabular}

Obs.: Os valores percentuais entre parêntesis representam a eficiência de remoção

o oxigênio tende a prejudicar o processo de redução, pois as moléculas de oxigênio são aceptoras de elétrons ${ }^{22}$. Trabalho feito por Cho et $a l^{22}$ ressalta esta característica do OD, mostrando que a efetiva eliminação de $E$. coli através da fase oxidativa da fotocatálise heterogênea, com $\mathrm{TiO}_{2}$ em suspensão, só é satisfatória quando há saturação do meio aquoso com OD.

A alcalinidade esteve ausente em todos os afluentes, devido à acidificação para pH 3 de todas as amostras. No entanto, houve aparecimento de alcalinidade na maioria dos efluentes; sugere-se que a reposição de volume - efetuada em todos os experimentosseja a responsável por esse aparecimento, pois a mesma foi feita com água do abastecimento público sem ajuste de $\mathrm{pH}$ (o $\mathrm{pH}$ desta água é levemente alcalino). A presença dos íons que representam a alcalinidade $\left(\mathrm{HCO}_{3}^{-}\right.$e $\left.\mathrm{CO}_{3}^{-2}\right)$ interfere negativamente no tratamento de compostos orgânicos. Segundo Legrini, Oliveiros e Braun apud Teixeira e Jardim ${ }^{23}$, o carbono inorgânico que compõe a alcalinidade pode competir com o carbono orgânico na fase oxidativa da fotocatálise heterogênea, através do seqüestro de radicais hidroxila. Trabalho feito por Aranã et al. ${ }^{24}$, durante o tratamento de águas residuárias da Universidade de Las Palmas de Gran Canaria com fotocatálise heterogênea com $\mathrm{TiO}_{2}$ em suspensão, mostrou que houve consumo de 7,23 ppm de alcalinidade durante o processo.

Na Tabela 1 observa-se também que o menor valor de remoção de turbidez ocorreu nos experimentos com luz solar (57\%), enquanto que naqueles com radiação de lâmpadas o menor valor foi de $34 \%$. Assim, a fotocatálise heterogênea é mais eficiente para remover turbidez quando a fonte luminosa é o sol. Para a boa eficiência da fotocatálise heterogênea, é necessária a remoção de turbidez pois, segundo Rincón e Pulgarin apud Ferreira e Daniel ${ }^{14}$, a turbidez elevada dificulta a penetração da luz no interior da solução aquosa devido ao efeito de dispersão; por conseguinte, será menor a quantidade de fótons que chegará até as partículas de $\mathrm{TiO}_{2}$.
Trabalho de Rodrigues et al. ${ }^{25}$ mostrou que quanto mais turva for a amostra menor será a eficiência de remoção de bactérias indicadoras de contaminação fecal, ou seja, a quantidade de radicais hidroxila ficou comprometida pela menor taxa de absorção de fótons pelo $\mathrm{TiO}_{2}$.

Os dados de SST e SSV na Tabela 1 permitem constatar que os experimentos com radiação UV-solar apresentaram melhor rendimento que aqueles com radiação UV-artificial. Os valores mínimos de remoção de SST e SSV com radiação UV-solar foram $26 \%$, enquanto que com a radiação UV-artificial os menores valores foram 14\%. A remoção de sólidos suspensos em amostras contendo $\mathrm{Cr}(\mathrm{VI})$ é de extrema importância, uma vez que o mesmo é capaz de se adsorver a partículas em suspensão na água, podendo ser transportados por longas distâncias em águas naturais, como rios, ou irem compor o sedimento de fundo do corpo hídrico ${ }^{1}$.

Na Figura 5 estão os dados referentes ao decaimento relativo da matéria orgânica através da DQO. Novamente, a radiação solar permitiu uma melhor eficiência que a radiação com lâmpadas, visto que o menor valor de remoção de DQO foi de 61 e $53 \%$ para experimentos com UV-solar e UV-artificial, respectivamente. O melhor desempenho da etapa oxidativa está diretamente relacionado com a efetiva captação de elétrons que migraram para a $\mathrm{BC}$ após a absorção de fótons pelo $\mathrm{TiO}_{2}$. A captação de elétrons por aceptores, no caso o $\mathrm{Cr}(\mathrm{VI})$ presente em solução, não permite o regresso dos mesmos para a $\mathrm{BV}$, assim estas produzem uma maior quantidade de radicais hidroxila a partir da captação de elétrons das hidroxilas $\left(\mathrm{OH}^{-}\right)$e das moléculas de água adsorvidas à partícula no $\mathrm{TiO}_{2}$. Com os dados de remoção de $\mathrm{Cr}(\mathrm{VI})$, deduz-se que houve maior quantidade de migração de elétrons com absorção de energia solar pelo fotocatalisador, portanto, houve maior captação de elétrons pelo $\mathrm{Cr}(\mathrm{VI})$ e conseqüente aumento de radicais hidroxila disponíveis em solução. Na Figura 6 estão os dados do decaimento 
relativo de $\mathrm{Cr}(\mathrm{VI})$, ao longo de $4 \mathrm{~h}$, dos experimentos feitos com UV-solar e UV-artificial. É possível observar que a etapa de redução da fotocatálise heterogênea é mais eficaz com radiação solar, pois o menor valor relativo de remoção de $\mathrm{Cr}(\mathrm{VI})$ nos experimentos da segunda etapa foi de $62 \%$, enquanto que na terceira etapa a menor remoção foi de 52\%. Sugere-se que a incidência simultânea de raios ultravioleta $\mathrm{A}$ e $\mathrm{C}$, da luz do sol, disponibilize maior quantidade de fótons absorvíveis pelo $\mathrm{TiO}_{2}$, por conseguinte, haja maior oferta de elétrons na banda de condução. Como abordado em relação aos resultados de OD, possivelmente o aumento da concentração do OD pode ter afetado negativamente a remoção de $\mathrm{Cr}(\mathrm{VI})$. Essa competição é possível pelo fato de as etapas de redução e oxidação não serem seletivas, ou seja, qualquer substância passível de redução e/ou oxidação pode participar do processo fotocatalítico heterogêneo ${ }^{11}$.

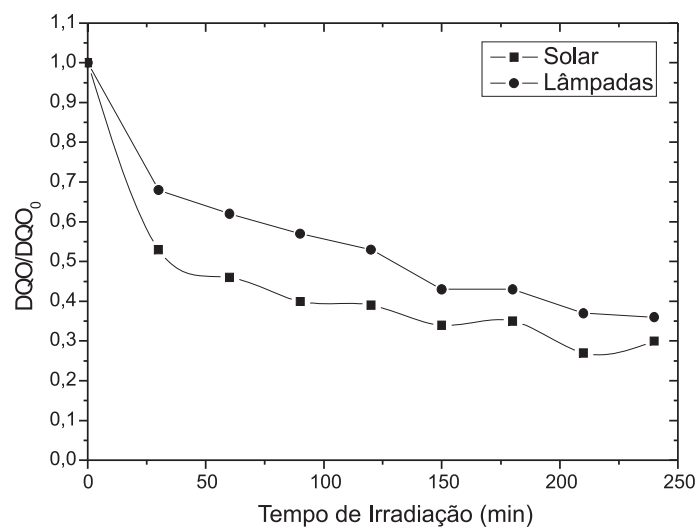

Figura 5. Remoção relativa de $D Q O / D Q O_{o}$ dos experimentos feitos com radiação solar e com lâmpadas germicidas

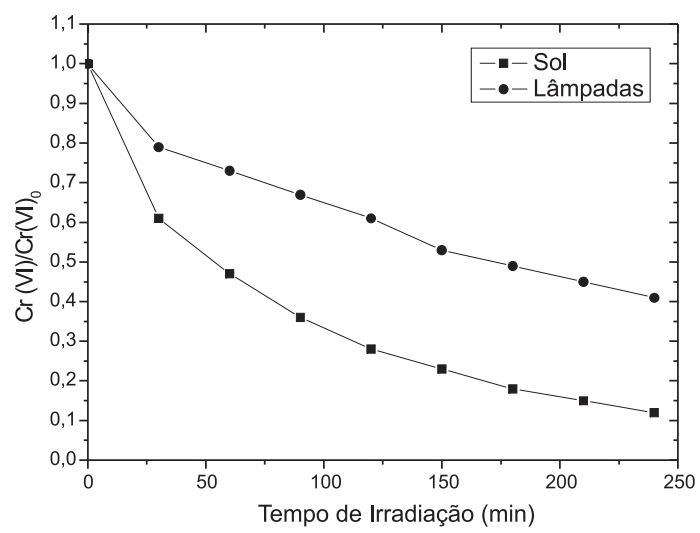

Figura 6. Remoção relativa de $\mathrm{Cr}(\mathrm{VI}) / \mathrm{Cr}(\mathrm{VI})_{0}$ dos experimentos feitos com radiação solar e com lâmpadas germicidas

As Figuras 5 e 6 também permitem constatar que, em média, houve uma remoção final de 88 e 59\% para DQO e de 64 e $70 \%$ de $\mathrm{Cr}(\mathrm{VI})$ para experimentos utilizando radiação UV-solar e UV-artificial, respectivamente. A alta eficiência de remoção de DQO e Cr(VI) - todos acima de $50 \%$ - é devido ao fenômeno da adsorção. Em meio aquoso ácido com $\mathrm{pH}$ abaixo de 6,25 o $\mathrm{TiO}_{2}$ fica com carga positiva e acima deste valor fica com carga negativa. Assim, as espécies com cargas negativas em meio ácido não sofrem repulsão eletrostática. $\mathrm{Na}$ faixa de $\mathrm{pH}$ entre 1 e 6, a espécie de $\mathrm{Cr}(\mathrm{VI})$ predominante é o $\mathrm{HCrO}_{4}^{-}$, podendo coexistir com a espécie $\mathrm{CrO}_{7}^{-2} \mathrm{em}$ concentrações acima de $10^{-3} \mathrm{~mol} \mathrm{~L}^{-1}$. A efetiva adsorção do $\mathrm{Cr}(\mathrm{VI})$ à superfície do $\mathrm{TiO}_{2}$ permitiu a captura de elétrons da banda de condução do fotocatalisador, quando este se polarizou ao receber fótons. Com isso, o elétron na $\mathrm{BC}$ não retornou para a $\mathrm{BV}$, permitindo que houvesse a captação de elétron da hidroxila $\left(\mathrm{OH}^{-}\right)$pela banda de valência, formando o radical hidroxila $(\bullet \mathrm{OH})$ que é o maior responsável pela mineralização da matéria orgânica. A mineralização da matéria orgânica reduzirá os valores dos sólidos suspensos, DQO e turbidez ${ }^{18,26-28}$. De acordo com Monn et al. ${ }^{26}$, as Equações que se seguem representam o estado do $\mathrm{TiO}_{2}$ em meio aquoso.

$$
\begin{gathered}
\left.>\mathrm{TiO}_{2}+\mathrm{H}^{+} \leftrightarrow\right\rangle \mathrm{Ti}-\mathrm{OH}_{2}{ }^{+} \\
\operatorname{carga}(+)(\mathrm{pKa} 1=4,5) \\
>\mathrm{Ti}-\mathrm{OH}+\mathrm{OH} \leftrightarrow\rangle \mathrm{Ti}-\mathrm{O}^{-}+\mathrm{H}_{2} \mathrm{O} \\
\operatorname{carga}(-)(\mathrm{pKa} 2=8,0)
\end{gathered}
$$

As Tabelas 2 e 3 apresentam os valores das constantes cinéticas obtidas com os experimentos feitos com radiação solar e artificial, respectivamente. Na Tabela 2, pode-se observar que a fase de redução da fotocatálise heterogênea possui maior eficiência que a etapa de oxidação, visto que os valores cinéticos de redução de $\mathrm{Cr}$ (VI) são maiores que os da oxidação da matéria orgânica. Esse mesmo comportamento ocorreu com os dados cinéticos dos experimentos com radiação artificial. Ao se comparar todos os experimentos, novamente constata-se que a cinética dos experimentos realizados em exposição ao sol é maior que a dos experimentos expostos a lâmpadas. Com os dados referentes às constantes cinéticas observa-se que a cinética da fotocatálise heterogênea seguiu o modelo de Langmuir-Hinshelwood, mostrando que as reações de oxidação e de redução são de pseudo-primeira ordem. As constantes cinéticas referentes à fase de oxidação da fotocatálise heterogênea apresentaram valores inferiores às menores constantes cinéticas obtidas por Ferreira e Daniel ${ }^{14}$, que foram de 0,016 e $0,021 \mathrm{~min}^{-1}$ para inativação de E. coli, e por Goswami, Mathur e Jotshi $^{29}$ que obtiveram $0,0263 \mathrm{~min}^{-1}$ para a remoção de benzeno através da fotocatálise heterogênea.

Tabela 2. Constantes cinéticas referentes à redução de $\mathrm{Cr}(\mathrm{VI}) \mathrm{e}$ oxidação de matéria orgânica utilizando radiação solar

\begin{tabular}{ccccc}
\hline Variável & \multicolumn{2}{c}{$\mathrm{Cr}(\mathrm{VI})$} & \multicolumn{2}{c}{$\mathrm{DQO}$} \\
\hline Experimento & $\mathrm{k}\left(\mathrm{min}^{-1}\right)$ & $\mathrm{R}^{2}$ & $\mathrm{k}\left(\mathrm{min}^{-1}\right)$ & $\mathrm{R}^{2}$ \\
\hline 1 & 0,0109 & 0,9901 & 0,0081 & 0,3000 \\
2 & 0,0243 & 0,9837 & 0,0036 & 0,7366 \\
3 & 0,0127 & 0,9915 & 0,0039 & 0,8685 \\
4 & 0,0100 & 0,9859 & 0,0048 & 0,8336 \\
5 & 0,0072 & 0,9960 & 0,0037 & 0,8176 \\
6 & 0,0038 & 0,9744 & 0,0041 & 0,7223 \\
\hline
\end{tabular}

Tabela 3. Constantes cinéticas referentes à redução de $\mathrm{Cr}(\mathrm{VI})$ e oxidação de matéria orgânica utilizando radiação de lâmpadas germicidas

\begin{tabular}{ccccc}
\hline Variável & \multicolumn{2}{c}{$\mathrm{Cr}(\mathrm{VI})$} & \multicolumn{2}{c}{$\mathrm{DQO}$} \\
\hline Experimento & $\mathrm{k}\left(\mathrm{min}^{-1}\right)$ & $\mathrm{R}^{2}$ & $\mathrm{k}\left(\mathrm{min}^{-1}\right)$ & $\mathrm{R}^{2}$ \\
\hline $\mathrm{A}$ & 0,0027 & 0,9205 & 0,0037 & 0,8847 \\
$\mathrm{~B}$ & 0,0053 & 0,9763 & 0,0036 & 0,8660 \\
$\mathrm{C}$ & 0,0034 & 0,9645 & 0,0044 & 0,8449 \\
$\mathrm{D}$ & 0,0037 & 0,9921 & 0,0044 & 0,9172 \\
$\mathrm{E}$ & 0,0032 & 0,9944 & 0,0030 & 0,9477 \\
$\mathrm{~F}$ & 0,0032 & 0,9926 & 0,0041 & 0,9031 \\
\hline
\end{tabular}


É também observável que a matéria orgânica é mais sensível à evaporação da amostra, pois vê-se a flutuação dos pontos em torno da linha de tendência, especialmente nos períodos mais quentes do dia (11:00 até 12:00 h). A partir da Figura 7, vê-se que é por volta das 12:00 h que há os maiores valores médios de incidência de radiação UV-solar. Segundo Cho et al. ${ }^{22}$, a temperatura do ar também influência a quantidade de luz incidente sobre uma superfície, pois suas pesquisas mostraram que o aumento da temperatura causa aumento da incidência de radiação $\mathrm{UV}$, devido à melhora da eficácia de difusão da radiação. Segundo Luiz e Moreira e Rosa apud Nogueira $^{17}$, os países situados entre as latitudes de $32^{\circ} \mathrm{N}$ e $32^{\circ} \mathrm{S}$ podem aproveitar cerca de $84 \%$ da energia solar incidente (a exemplo do Brasil, que se situa na faixa de $5^{\circ} \mathrm{N}$ até $32^{\circ} \mathrm{S}$ ).

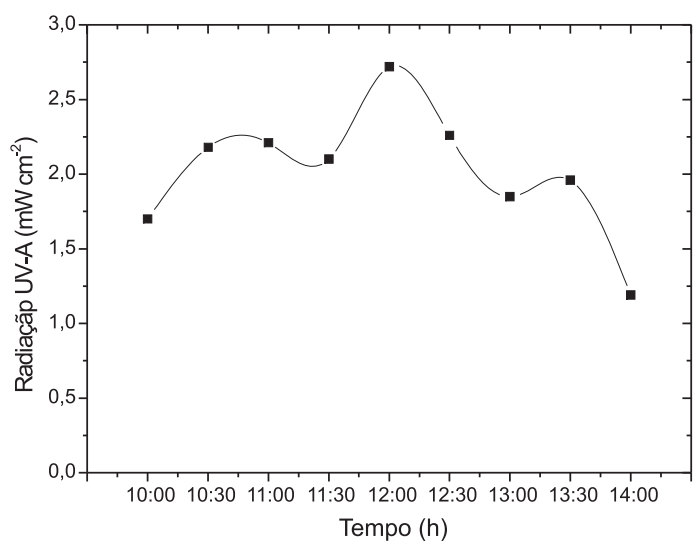

Figura 7. Valores médios da radiação UV-A solar $\left(\mathrm{mW} \mathrm{cm}^{-2}\right)$ em cada período de tempo

\section{CONCLUSÕES}

A partir dos resultados apresentados conclui-se que a fotocatálise heterogênea pode ser aplicada no polimento final de efluentes industriais com significativas concentrações de material orgânico e de $\mathrm{Cr}(\mathrm{VI})$. Conclui-se também que as fases de redução e oxidação da fotocatálise heterogênea possuem melhor desempenho quando a fonte luminosa é o sol, visto que as constantes cinéticas obtidas mostraram resultados mais elevados quando a radiação ultravioleta foi de origem solar.

\section{REFERÊNCIAS}

1. Jordão, C. P.; da Silva, A. C.; Pereira, J. L.; Brune, W.; Quim. Nova 1999 , $22,47$.
2. http://www.enq.ufrgs.br/dequi/pos/projetos/curtume/arqs/ artigo_cobeq_curtume.pdf, acessada em Outubro 2005.

3. http://www.icp.csic.es/cyed/monografiasteneria/capituloiv.pdf, acessada em Abril 2005.

4. Dias, M. C. O.; Pereira, M. C. B.; Dias, P. L. F.; Virgílio, F.; Manual de Impactos Ambientais: orientações básicas sobre aspectos ambientais de atividades produtivas, Banco do Nordeste: Fortaleza, 1999.

5. Gomes, L. A.; Lima, M. G. S.; Pedroza, M. M.; Araújo, M. M.; Anais do Congresso Brasileiro de Engenharia Sanitária e Ambiental, Joinville, Brasil, 2003.

6. Verma, T.; Srinath, T.; Gadpayle, R. U.; Ramteke, P. W.; Hans, R. K.; Garg, S. K.; Bioresour. Technol. 2001, 78, 31.

7. Srinath, T.; Verma, T.; Ramteke, P. W.; Garg, S. K.; Chemosphere 2002, $48,427$.

8. Schrank, S. G.; Tese de Doutorado, Universidade Federal de Santa Catarina, Brasil, 2003.

9. http://www.ceset.unicamp.br/ite/artigos/3fec2404.pdf, acessada em Julho 2005.

10. Zaidi, A. H.; Crittenden, J. C.; Hand, D. W.; Perral, D. L.; Proceedings of the 1995 American Solar Energy Society Annual Conference, Minnesota, EUA, 1995.

11. Baird, C.; Química Ambiental, 2a ed., Bookman: Porto Alegre, 2002.

12. Lima, C. A. P.; Tese de Doutorado, Universidade Federal da Paraíba, Brasil, 2002.

13. Schrank, S. G.; José, H. J.; Moreira, R. F. P. M.; J. Photochem. Photobiol., A 2002, 147, 71 .

14. Ferreira, I. V. V.; Daniel, L. A.; Revista de Engenharia Sanitária Ambiental 2004, 9, 335

15. Daniel, L. A.; Processos de desinfecção e desinfetantes alternativos na produção de água potável, Projeto PROSAB, Rima, ABES: Rio de Janeiro, 2001.

16. Goswami, D. Y.; Advances in Solar Energy: an Annual Review of Research and Development, Library of Congress, Colorado, 1995, chapter 3.

17. Nogueira, R. F. P.; Tese de Doutorado, Universidade Estadual de Campinas, Brasil, 1995.

18. Cho, Y.; Choi, W.; J. Photochem. Photobiol., A 2002, 148, 129.

19. Vieira, M. F. A.; Costa, M. A. S. M.; Bastos, S. A.; Campos, A. M. B.; Figueiredo, F. C.; Barros, D. G. R.; Anais do Congresso Brasileiro de Engenharia Sanitária e Ambiental, Joinville, Brasil, 2003.

20. APHA; Standard Methods for the Examination of Water and Wastewater, $15^{\text {th }}$ ed., Washington, DC., 1998.

21. Srithar, K.; Mani, A.; Pergamon 2003, 30, 505

22. Cho, M.; Chung, H.; Choi, W.; Yonn, J.; Water Res. 2004, 38, 1069.

23. http://www.iqa.iqm.unicamp.br/cadernos/ cadernopoa1.pdf, acessada em Maio 2005.

24. Aranã, J.; Melián, J. A. H.; Rodríguez, J. M. D.; Diaz, O. G.; Viera, A.; Penã, J. P.; Sosa, P. M. M.; Jiménez, V. E.; Catal. Today 2002, 76, 279.

25. Rodrigues, C. P.; Ziolli, R. L.; Guimarães, J. R.; Figueiredo, R. F.; Anais do XXVII Congresso Interamericano de Engenharia Sanitária e Ambiental, Porto Alegre, Brasil, 2000.

26. Moon, J.; Yun, C. Y.; Chung, K. W.; Kang, M. S.; Yi, J.; Catal. Today 2003, $87,77$.

27. Rincón, A. G.; Pulgarin, C.; Appl. Catal., B 2003, 44, 263.

28. Sena, M. M.; Collins, C. H.; Collins, K. E.; Scarmínio, I. S.; Quim. Nova 2001, 24, 331 .

29. Goswami, D. Y.; Mathur, G. D.; Jotshi, C. K.; Engineering Systems Design and Analysis 1994, 3, 64 